\title{
Investigation of the NOTCH3 and TNFSF7 Genes on C19p13 as Candi- dates for Migraine
}

\author{
Robert A. Smith ${ }^{1}$, Robert Curtain ${ }^{1}$, Mick Ovcaric ${ }^{1}$, Lotti Tajouri ${ }^{1}$, John MacMillan ${ }^{2}$ and \\ Lyn Griffiths*, \\ ${ }^{I}$ Genomics Research Centre, School of Medical Science, Griffith University, Gold Coast, Queensland, Australia \\ ${ }^{2}$ Queensland Clinical Genetics Service, Royal Children's Hospital Health Service District, Brisbane, Queensland, Aus- \\ tralia
}

\begin{abstract}
To investigate the migraine locus around the C19p13 region through analysis of the NOTCH3 gene (C19p13.2p13.1), previously shown to be a gene involved in CADASIL and the TNFSF7 gene (C19p13), homologous to the ligands of TNF-alpha and TNF-beta, genes that have previously been associated with migraine. The NOTCH3 gene was analysed by sequencing all exons with known CADASIL mutations in a typical (non-familial hemiplegic) migraine family (MF1) that has previously been shown to be linked to C19p13. The TNFSF7 gene was investigated through SNP association analysis using a matched case-control migraine population. NOTCH3 gene sequencing results for affected members of MF1 proved to be negative for all known sequence variants giving rise to mutations for CADASIL. TNFSF7 gene chisquare results showed non-significant $P$ values across all populations tested against controls, except for the MO subgroup which displayed a possible association with the TNFSF7 SNP (genotype, allele analysis $P=0.036, P=0.017$ respectively). Our results suggest that common migraine is not caused by any known CADASIL mutations in the NOTCH3 gene of interest. However, the TNFSF7 gene displayed signs of involvement in a MO affected population and indicates that further independent studies of this marker are warranted.
\end{abstract}

Keywords: Typical migraine, NOTCH3, CADASIL, TNFSF7, C19p13, MO.

\section{INTRODUCTION}

Typical migraine is a common debilitating disorder affecting approximately $12 \%$ of the Western population [1]. A large US epidemiological study indicated that the disease affects around $18 \%$ of women and $12 \%$ of men in the overall population [2]. The disease has two main subtypes, migraine without aura (MO) affecting $~ 73 \%$ and migraine with aura (MA) affecting about $33 \%$. Migraine with aura is defined as the more severe type and both subtypes can occur within the same family. The number of genes involved in common migraine is unknown; although genes for a rare severe sub-type of migraine Familial Hemplegic Migraine (FHM) have been identified on chromosome 19 [3] and recently FHM type 2 has been identified on chromosome 1 [4].

Mutations in the neuronal calcium channel gene (CACNA1A) on 19p13.1-13.2 have been shown to cause FHM [3]. Calcium channel genes may also be involved in typical migraine (MA and MO) as some studies have indicated that the FHM locus may contribute to migraine with and without aura [5]. We have previously reported linkage in one large typical migraine family [6] to the CACNA1A region on chr19. Also in a study by Terwindt et al. (1998) [7] the authors detected an FHM mutation in the CACNA1A gene in a typical migraine patient with MA, suggesting that FHM may be a rare and severe form of MA.

\footnotetext{
*Address correspondence to this author at the Genomics Research Centre, School of Medical Science, Griffith University Gold Coast, Queensland, 4222, Australia; E-mail: 1.griffiths@griffith.edu.au
}

Typical migraine has been extensively studied on chromosome 19 showing positive linkage to causal markers in the C19p13 area [5,6,8-10], but only in FHM has the chromosome 19 gene and mutations within been identified [3]. The NOTCH3 gene on C19p13.2-p13.1 has previously been shown to be a gene involved in CADASIL (cerebral autosomal dominant arteriopathy with subcortical infarcts and leukoencephalopathy) [11]. CADASIL is an inherited stroke syndrome that leads to dementia. The key features of the disorder are migraine, recurrent subcortical events, and dementia, in association with diffuse white matter abnormalities on neuroimaging [12]. The gene encodes a large transmembrane receptor [13], which has been shown to be expressed in vascular smooth muscle cells in adult human tissues [14]. In a study by Joutel et al. 1997 [13] this large gene, containing 33 exons, was found to contain a cluster of mutations in exons 3 and 4 affecting 64\% (32/50) of tested patients with the CADASIL disorder. Of the other $36 \%$ of CADASIL sufferers, 26\% (13/50) have mutations in exons $2,5,11,14,18,19,22$ or 23 and the other $10 \%(5 / 50)$ had no detectable mutation in the NOTCH3 gene [13]. Mutations identified to date in NOTCH3 have all been missense mutations involving a loss or gain of a cysteine amino acid residue [13].

The NOTCH3 gene may also be implicated in migraine, as migraine shows some symptomatic overlap with CADASIL. This has been suggested from studies performed by Hutchinson et al. (1995) [15] and Verin et al. (1995) [16] where the authors have found some correlations between the two disorders. Hutchinson et al. (1995) [15] used MRI to 


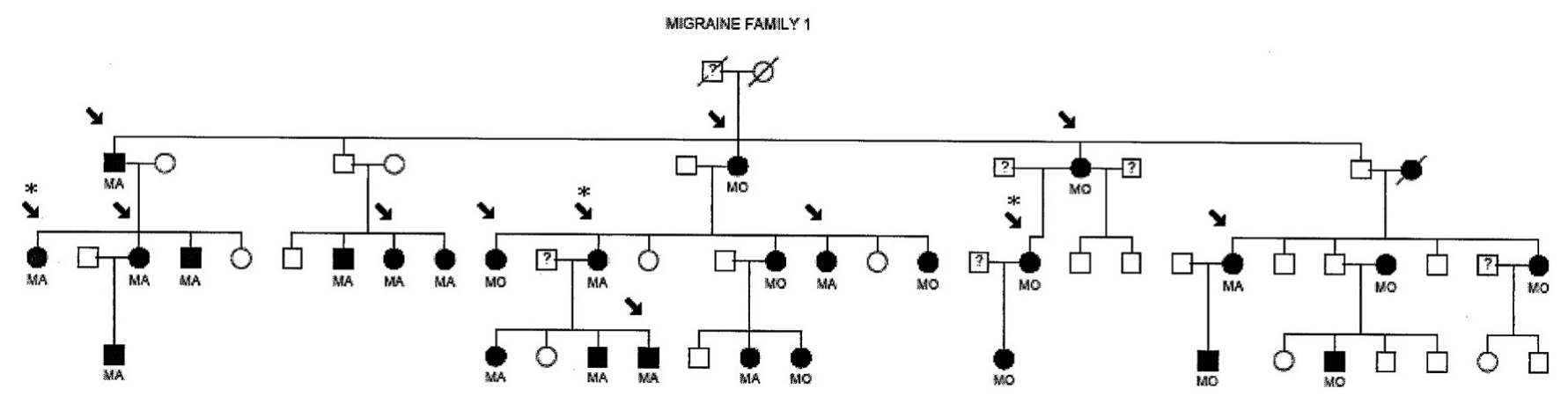

Fig. (1). Migraine family 1 (MF1) Individuals in black have been diagnosed as MA or MO. Non-migraine individuals are in clear. Samples tested are indicated by an arrow. Samples indicated by asteric $\left(^{*}\right)$ were sequenced for all known CADASIL mutations in the NOTCH3 gene.

study 15 members of an Irish family, 10 of whom had evidence of CADASIL. Five members of this family had hemiplegic migraine. They proposed that hemiplegic migraine may be an allelic disorder to CADASIL. Migraine with aura (MA) is also included as one of the clinical hallmarks of CADASIL, with many CADASIL patients showing an unusually high frequency of attacks of migraine with atypical aura [17]. In 2003, Oberstein et al. [18] found that among 6 individuals who carried a mutation in the NOTCH3 gene, there was an increase in white matter hyperintensities on brain MRI, compared to controls and migraine with aura was more common in these subjects than in their controls. In addition, a recent association study by Schwaag et al. identified a significant association of the synonymous rs 1043994 polymorphism with migraine [19]. However, not all NOTCH3 mutations may be involved in migraine, as an association study by Borroni et al. [20] indicated that the that functional polymorphism T6746C of NOTCH3 did not have any association with migraine in the tested Italian population.

The TNFSF7 gene (Tumor Necrosis Factor Ligand Superfamily, member 7) localized on C19p13 is a surface antigen found on activated, but not resting, T and B lymphocytes [21]. It is a 19 amino acid protein containing a 20 -amino acid hydrophilic $\mathrm{N}$-terminal domain that lacks a signal sequence; an 18-amino acid hydrophobic region that presumably functions as a transmembrane anchor; and a C-terminal domain that contains 2 potential $\mathrm{N}$-linked glycosylation sites is extracellular classifying TNFSF7 as a type II transmembrane protein. TNFSF7 is homologous to the ligands of the TNF receptor family, including TNF-alpha, TNF-beta and the CD40 ligand, showing 19 to $24 \%$ amino acid sequence identity in the extracellular region. [21]. TNF-alpha and TNFbeta have both been previously associated with migraine. Rainero et al. 2004 [22], recently found an association between the tumor necrosis factor-alpha -308 G/A gene polymorphism and migraine. In a group of 299 migraine patients and 306 control subjects, the association of this polymorphism with the occurrence and clinical characteristics of migraine was tested. They found that homozygosity for the $G$ allele was associated with an increased risk of migraine (odds ratio $[\mathrm{OR}]=2.85, \mathrm{p}<0.001$ ) [22]. Also Empl et al. 2003 [23] suggested that TNF-alpha could contribute to migraine pain generation and in their study of TNF-alpha and its soluble receptor sTNF-RI, they found that migraine patients tended to have less concentration levels of sTNF-RI
$(794+/-158 \mathrm{pg} / \mathrm{ml})$ than controls $(945+/-137 \mathrm{pg} / \mathrm{ml})$ [23]. The authors suggested that if TNF-alpha plays a role in migraine physiopathology, migraine patients may lack sufficient antagonistic sTNF-RI to neutralize hyperalgesic TNFalpha during a migraine attack, causing pain [23]. The TNFbeta gene has been associated with migraine without aura. Trabace et al. 2002 [24] found the frequency of the TNFB*2 allele of the TNF-beta gene was significantly increased in patients with migraine without aura as compared with the control group (78.72\% versus $61.4 \%, \mathrm{Pc}=.004)$ [24]. They stated that carriage of the TNFB*2 allele confers a high risk for the development of migraine without aura. The data supported the hypothesis that TNF-beta could be a susceptibility gene in migraine without aura [24]. Since TNFSF7 is homologous to the ligands of the TNF receptor family i.e. TNF-alpha and TNF-beta, (and is localized to a migraine susceptibility area at C19p13) we decided to investigate this gene for association with migraine.

This study investigated the migraine susceptibility locus C19p13 by testing two genes, from this genomic region, that may possibly be involved in the disorder. The NOTCH3 gene was analysed by sequencing all exons with known CADASIL mutations through a family previously linked to C19p13 [6]. The TNFSF7 gene was also investigated using SNP case-control association analysis in a population of migraineurs and matched controls.

\section{MATERIALS AND METHODOLOGY}

\section{Subjects}

The subjects who participated in this study were all of Australian Caucasian origin and were diagnosed for migraine by a detailed questionnaire and a clinical neurologist in accordance to the International Headache Society guidelines [25]. The control population consisted of individuals who indicated on a questionnaire that they had never suffered from migraine or any similar condition and that none of their first or second degree relatives suffered from migraine or similar conditions. This research was approved by the Griffith University Ethics Committee and all subjects participating in the study gave consent. Blood samples for the pedigree population as well as the association population were collected through the Genomics Research Centre clinic. Genomic DNA, from these patients, was extracted utilizing DNA extraction methods described previously $[26,27]$. 
Table 1. A List of all Published Mutations of CADASIL from the Notch3 Gene (Human Gene Mutation Data Base Cardiff

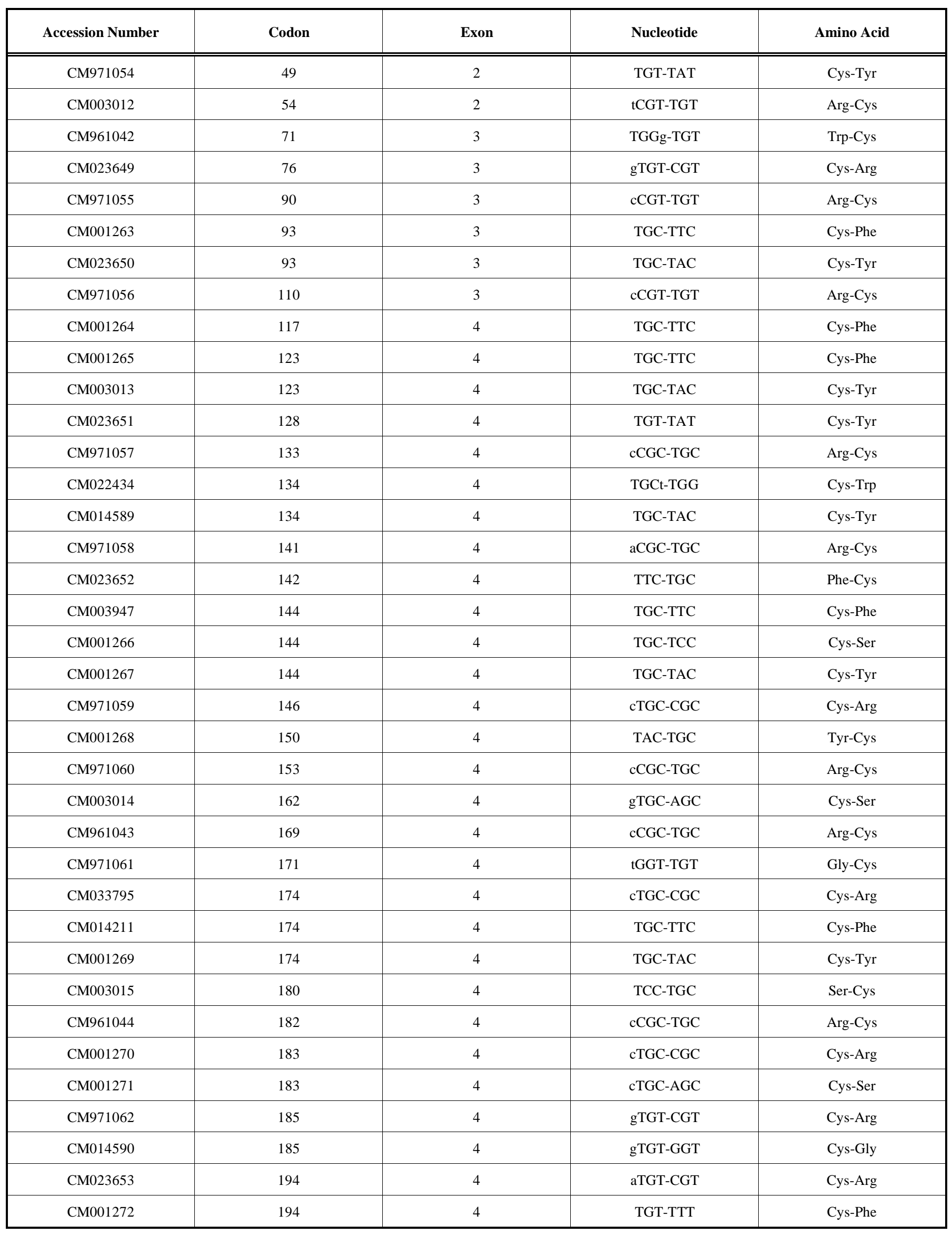


(Table 1). Contd.....

\begin{tabular}{|c|c|c|c|c|}
\hline Accession Number & Codon & Exon & Nucleotide & Amino Acid \\
\hline CM003016 & 194 & 4 & TGT-TAT & Cys-Tyr \\
\hline CM003017 & 206 & 4 & TGC-TAC & Cys-Tyr \\
\hline CM003018 & 207 & 4 & cCGT-TGT & Arg-Cys \\
\hline CM971063 & 212 & 4 & cTGC-AGC & Cys-Ser \\
\hline CM033796 & 213 & 4 & AGG-AAG & Arg-Lys \\
\hline CM971064 & 222 & 4 & cTGT-GGT & Cys-Gly \\
\hline CM023654 & 222 & 4 & TGT-TAT & Cys-Tyr \\
\hline CM971065 & 224 & 4 & TGT-TAT & Cys-Tyr \\
\hline CM023655 & 233 & 5 & tTGT-AGT & Cys-Ser \\
\hline CM023656 & 251 & 5 & aTGC-CGC & Cys-Arg \\
\hline CM971066 & 258 & 5 & TAT-TGT & Tyr-Cys \\
\hline CM014070 & 332 & 6 & cCGC-TGC & Arg-Cys \\
\hline CM023657 & 420 & 8 & cGGT-TGT & Gly-Cys \\
\hline CM014591 & 428 & 8 & TGT-TCT & Cys-Ser \\
\hline CM023658 & 440 & 8 & cTGC-GGC & Cys-Gly \\
\hline CM023659 & 449 & 8 & cCGC-TGC & Arg-Cys \\
\hline CM021648 & 455 & 8 & cTGT-CGT & Cys-Arg \\
\hline CM961045 & 542 & 11 & TGT-TAT & Cys-Tyr \\
\hline CM994179 & 544 & 11 & tCGC-TGC & Arg-Cys \\
\hline CM961046 & 558 & 11 & tCGC-TGC & Arg-Cys \\
\hline CM961047 & 578 & 11 & aCGC-TGC & Arg-Cys \\
\hline CM003019 & 607 & 11 & cCGC-TGC & Arg-Cys \\
\hline CM971067 & 728 & 14 & cCGC-TGC & Arg-Cys \\
\hline CM023660 & 953 & 18 & cGGC-TGC & Gly-Cys \\
\hline CM003020 & 984 & 18 & TTC-TGC & Phe-Cys \\
\hline CM971068 & 985 & 18 & cCGC-TGC & Arg-Cys \\
\hline CM971069 & 1006 & 19 & cCGC-TGC & Arg-Cys \\
\hline CM994180 & 1015 & 19 & cTGC-CGC & Cys-Arg \\
\hline CM023661 & 1021 & 19 & TAT-TGT & Tyr-Cys \\
\hline CM971070 & 1031 & 19 & aCGC-TGC & Arg-Cys \\
\hline CM014592 & 1058 & 20 & gGGT-TGT & Gly-Cys \\
\hline CM971071 & 1231 & 22 & cCGT-TGT & Arg-Cys \\
\hline CM961048 & 1261 & 23 & gTGC-CGC & Cys-Arg \\
\hline
\end{tabular}

www.uwcm.ac.uk/uwcm/mg/ns/1/361163.html).

For mutation analysis, 12 affected DNA samples obtained from migraine family 1 (MF1) (Fig. 1), a pedigree showing linkage to $19 \mathrm{p} 13$ in a previous study [6], were screened for the known exon 3 and exon 4 CADASIL mutations (Table 1) in the NOTCH3 gene. The pedigree family members tested (indicated by an arrow in Fig. 1) were mi- graine sufferers of which eight were diagnosed MA and four MO affected, two were males (both MA affected) and ten females (six MA and four MO affected). The age of these migraine affected pedigree members range from 31 to 87 years. 
Secondly 3 of the 12 family members, from three separate branches of MF1 (Fig. 1), were further screened by sequencing the rest of all known exons containing CADASIL mutations in the NOTCH3 gene (Table 1). The association study included a case-control population of 220 migraineurs and 220 sex, age and ethnicity matched controls.

Table 2. Primer Sequences Utilized for Sequencing of the NOTCH3 for the CADASIL Mutations

\begin{tabular}{|c|c|}
\hline NOTCH3 region & Sequence $5^{\prime}->3^{\prime}$ \\
\hline \multirow{2}{*}{ Exon 2} & F-TCСТCСАССТTССТTCAC \\
\hline & R-ACACACAGGGCCCACTGGT \\
\hline \multirow{2}{*}{ Exon 3} & F-TGTGCTGCCCAACCAAGCCA \\
\hline & R-ACTGACCACACCCCCGACTA \\
\hline \multirow{2}{*}{ Exon 4} & F-TAGTCGGGGGTGTGGTCAGT \\
\hline & R-СCTCTGACTCTCCTGAGTAG \\
\hline \multirow{2}{*}{ Exon 5} & F-TGACCATCCTTGCCCCCTT \\
\hline & R-CTGGCCTGTGGCACACAGAT \\
\hline \multirow{2}{*}{ Exon 6} & F-TGGACTGCTGCATCTGTGTG \\
\hline & R-ACACGCCTGTGGCACAGTCA \\
\hline \multirow[b]{2}{*}{ Exon 8} & F-ATCGCACTCCATCCGGCA \\
\hline & R-ACCCACCTGCCATACAGA \\
\hline \multirow{2}{*}{ Exon 11A } & F-ATTGGTCCGAGGCCTCACTT \\
\hline & R-ACCTGGCTCTCGCAGCGTGT \\
\hline \multirow{2}{*}{ Exon 11B } & F-CCATTCCCAACCCCTCTGTG \\
\hline & R-TGCCTGTGCTCCTGGCTACA \\
\hline \multirow{2}{*}{ Exon 14} & F-TCCCTGGCCTGACTACCTTC \\
\hline & R-CTGCAGAGGGAAGGTGAGGT \\
\hline \multirow[b]{2}{*}{ Exon 18} & F-GATCCTCCCTCCCACTCCTT \\
\hline & R-AGGTCCCCAGTAACTCCA \\
\hline \multirow[b]{2}{*}{ Exon 19} & F-ACTGACTCTAAGTGCTTCCC \\
\hline & R-AGCAGGAGGTACGTGCATGA \\
\hline \multirow{2}{*}{ Exon 20} & F-TGTTCCTGTGCCACTCTCCT \\
\hline & R-АССтССтСтTСССтСтсСт \\
\hline \multirow{2}{*}{ Exon $22 \mathrm{~A}$} & F-TTCСTCTTGACCACCССTCG \\
\hline & R-TGGCAGGCACCTGAGCGACA \\
\hline \multirow{2}{*}{ Exon $22 \mathrm{~B}$} & F-CAGGATACACTGGTTTGCGC \\
\hline & R-TGCCACGTTATGGATCAGCC \\
\hline \multirow{2}{*}{ Exon 23} & F-GATCTACATGCTCCCGCTCG \\
\hline & R-TACTCCTCCTCCATAGGCCG \\
\hline
\end{tabular}

\section{Mutation Analysis}

Mutation screening was performed by direct sequencing of exons, exhibiting known CADASIL mutations, in the NOTCH3 gene utilizing genomic DNA samples from migraine affected pedigree members of MF1 (Fig. 1). Templates of PCR DNA fragments were generated in the forward and reverse direction using standard PCR (outlined below in association study) and sequencing conditions (ABI protocols). Table 2 shows a list of exon primer sequences used in sequencing for the known mutations. The resulting products were electrophoresed on an ABI377 Sequencer (Applied Biosystems) and analysed using Sequencher software (Gene Codes Corporation) against a control sequence (Accession number: NM 000435).

\section{Association Analysis}

The TNFSF7 SNP, for association analysis, was selected utilizing the software SNPbrowser ${ }^{\mathrm{TM}}$ (ABI) and Ensembl Genome Browser, NCBI SNP databases. This synonymous coding SNP (refSNP 1862511, C/T variation, codes for amino acid Cysteine) is contained within exon 3 of the TNFSF7 gene with a minor allele frequency of approximately 0.3 ( $\mathrm{T}$ allele). Primer sequences for the SNP were designed by utilizing Primer Express ${ }^{\mathrm{TM}}$ v 2.0 software (ABI) and are displayed below.

Forward primer: 5'- AGCACTGGGCCGCTCC - 3'

Reverse primer:

\section{5' - CAAAAGTGTCCCAGTGAGGTTG - 3'}

The PCR reaction utilized final concentrations of $1.75 \mathrm{mM}, 0.2 \mu \mathrm{M}, 200 \mu \mathrm{M}, 1 \mathrm{X}$ and $1 \mathrm{U}$ for $\mathrm{MgCl}_{2}$, Primers, dNTPs, 10x Buffer and Taq polymerase, respectively. Approximately 40ng of DNA per reaction was used in the PCR. Cycling conditions for PCR consisted of $94^{\circ} \mathrm{C}$ for 4 minutes, then 35 cycles of $94^{\circ} \mathrm{C}$ for 1 minute and $60^{\circ} \mathrm{C}$ for 1 minute. The final PCR extension consisted of $72^{\circ} \mathrm{C}$ for 2 minutes.

SNP genotype analysis was performed using a restriction enzyme site that overlapped the SNP site (CTCCTC). Restriction enzyme digest conditions utilized 10ul of PCR product and a $10 \mathrm{ul}$ mix of $3 \mathrm{U}$ of restriction enzyme with $1 \mathrm{X}$ enzyme buffer and H2O. Digest products were loaded and electrophoresised on 3\% standard agarose gels running at 110 volts for 1 hour. The genotyping allele set and corresponding restriction digest fragment size consisted of: $\mathrm{C}$ allele $=192,100 \mathrm{bp}, \mathrm{T}$ allele $=292 \mathrm{bp}, \mathrm{C} / \mathrm{T}=292,192,100 \mathrm{bp}$.

Genotype and allele frequencies for the SNP variant were calculated from observed genotype counts. The expected genotype proportions according to the Hardy-Weinberg law were calculated and compared to observed genotypes as a control for systematic genotyping error and population stratification. Genotype and allele frequencies were initially assessed for association with migraine, then MA and MO populations were investigated using conventional contingency table analyses incorporating the standard chi-squared test for independence.

\section{RESULTS}

\section{Mutation Analysis}

The DNA samples from MF1 that were examined for NOTCH3 - CADASIL mutations were from individuals affected with typical migraine in a pedigree previously shown to be linked to chromosome 19 p13 [6]. Firstly 12 members from MF1 were screened for exon 3 and 4 mutations of the NOTCH3 gene using direct sequencing methods - a diagnostic screening process that is utilized first in detecting CADASIL mutations. The results revealed no variations 
or mutations detected in the sequence of the two exons within the twelve migraine family one DNA templates. Secondly, 3 members of MF1 were chosen from three separate pedigree branches to test for the rest of the exons with known CADASIL mutations in NOTCH3 (Table 1). These results also proved to be negative with no known sequence variants detected in the extended exon sequence analysis. The sequencing results displayed that of a normal coding sequence for the NOTCH3 gene (Accession number: NM 000435).

\section{Association Analysis}

Total distribution of the rs1862511 SNP genotype and allele frequencies of the TNFSF7 gene in Migraine (Total), MA, MO and Control Groups are displayed in Table 3.

The results of chi-square analysis of the TNFSF7 SNP (rs1862511) are displayed in Table 4. All population data of observed genotypes fitted the expected genotype proportions according to the Hardy-Weinberg law. Chi-square results showed non-significant $P$ values $(P>0.05)$ across all populations tested against controls. The only exception was for the MO subgroup which displayed a positive association for both alleles $(P=0.017)$ and genotypes $(P=0.036)$ for the TNFSF7 SNP (Table 4).

Table 3. Total Distribution for rs1862511 SNP Genotype and Allele Frequencies of the TNFSF7 Gene in Migraine (Total), MA, MO and Control Groups

\begin{tabular}{|c|c|c|c|}
\hline & \multicolumn{3}{|c|}{ SNP Genotypes } \\
\hline Group & C/C & C/T & T/T \\
\hline \hline Total Migraine & $116(53 \%)$ & $88(40 \%)$ & $15(7 \%)$ \\
\hline MA & $65(49 \%)$ & $59(44 \%)$ & $10(7 \%)$ \\
\hline MO & $51(60 \%)$ & $29(34 \%)$ & $5(6 \%)$ \\
\hline Control & $73(43 \%)$ & $81(48 \%)$ & $16(9 \%)$ \\
\hline & & SNP Alleles & \\
\hline Group & C & T & \\
\hline \hline Total Migraine & $320(73 \%)$ & $118(27 \%)$ & \\
\hline MA & $189(71 \%)$ & $79(29 \%)$ & \\
\hline MO & $131(77 \%)$ & $39(23 \%)$ & \\
\hline Control & $227(67 \%)$ & $113(33 \%)$ & \\
\hline
\end{tabular}

Table 4. Chi-Squared $\left(\chi^{2}\right)$ Analysis of all Migraine Groups Against Controls for rs1862511 SNP of the TNFSF7 Gene

\begin{tabular}{|c|c|c|}
\hline & \multicolumn{2}{|c|}{ Frequency Comparison } \\
\hline Group & Genotypes & Alleles \\
\hline \hline Total migraine & $\chi^{2}=4.00, P=0.136$ & $\chi^{2}=3.63, P=0.057$ \\
\hline MA & $\chi^{2}=1.06, P=0.589$ & $\chi^{2}=0.98, P=0.322$ \\
\hline MO & $\chi^{2}=6.65, P=0.036$ & $\chi^{2}=5.74, P=0.017$ \\
\hline
\end{tabular}

\section{DISCUSSION}

The procedure for genetic diagnostic testing for CADASIL mutations has recently been revised. We undertook a similar approach to this revision in testing for these mutations in common migraine. A study in Britain [28], found 15 different point mutations in the NOTCH3 gene in 48 families, $73 \%$ of which were in exon $4,8 \%$ in exon 3 , and $6 \%$ in each of exons 5 and 6 . The authors suggested that on the basis of this spectrum the suggested protocol for genetic diagnostic testing for CADASIL would be to screen exon 4 and proceed to mutational screening of exons 3,5 , and 6 where indicated [28]. A similar approach can be undertaken in diagnostic testing for other diseases with known mutations in genes causing a disorder, including FHM whereby two genes and corresponding mutations have been identified in causing this rare subtype of migraine.

The NOTCH3 gene has been localised to $\mathrm{C} 19 \mathrm{p} 13$, a region showing linkage to MF1 a typical (not FHM) migraine pedigree. Our sequencing results for this gene, specifically testing exons with known CADASIL mutations proved to be negative. These results indicate that common migraine, at least in this pedigree, is not caused by mutations in the NOTCH3 gene.

TNF-alpha and TNF-beta have both been previously associated with migraine $[22,24]$. Since TNFSF7 is localized to the same migraine susceptibility area at $\mathrm{C} 19 \mathrm{p} 13$ and shows homology to the ligands of the TNF-alpha and TNFbeta genes (both localized at C6p21.3), we decided to also investigate this gene for involvement in migraine. A suitable informative SNP (rs1862511) was selected for an association analysis study involving a matched case-control population. Overall chi-square results comparing migraine (total) and MA sub-populations with sex, age and ethnicity matched controls proved to be non-significant, with $P$ values of $P=$ $0.136, P=0.589$ respectively obtained (Table 4 ). These values were both above the threshold of $P<0.05$ for significance. However, the MO subgroup displayed signs of possible involvement of the TNFSF7 SNP with this subpopulation compared to controls. $P$ values for genotype and allele analysis were $P=0.036$ and $P=0.017$, respectively (Table 4). These results indicate that this genetic variant may play a role in migraine without aura and warrant further investigation.

Overall the results presented here do not support a relationship between NOTCH3 and common migraine. Although CADASIL patients often display migraine symptoms there was no evidence that CADASIL mutations from the NOTCH3 gene are involved in typical migraine in our C19p13 linked [6] migraine family samples. However, this does not discount the possibility of a role for mutations in the as yet unscreened exons in NOTCH3 in migraine susceptibility. The TNFSF7 gene also localized to the C19p13 region did not show any association with typical migraine or the MA subtype, however a weak association was found with MO affected individuals. Since this gene shows homology to the TNF receptor family and both TNF-alpha and beta have previously shown association with typical migraine [22, 24], the TNFSF7 gene (localized on C19p13, a migraine linked region, see [5,6,8-10]) was investigated in migraine. Our association study showed signs of possible involvement of this gene with the MO subtype only, but clearly more work 
needs to be done in increasing sample size numbers and also confirmation from other research groups to give an indication of a relationship of this gene to migraine without aura.

\section{CONCLUSION}

It is clear that typical migraine is a complex disorder that may involve several genes on various chromosomes. Since the C19p13 region has been implicated in a number of studies it is considered a 'hotspot' for the disorder. More extensive sequencing of the NOTCH 3 gene that may identify novel mutations that relate to migraine should be undertaken. Further studies need to be performed with TNFSF7 and MO affected individuals and also other possible TNF receptor family homologues on C19p13, such as TNFSF9 (C19p13.3) and TNFSF14 (C19p13.3) should be tested for migraine involvement. It may be useful to explore the TNF receptormigraine interaction further by studying these genes localized to the $\mathrm{C} 19 \mathrm{p} 13$ region.

\section{ACKNOWLEDGEMENTS}

This research was supported by funds from the National Health and Medical Research Council of Australia.

\section{REFERENCES}

[1] Stewart WF, Lipton RB, Celentano DD, Reed ML. Prevalence of migraine headache in the United States. JAMA 1992; 267: 64-69.

[2] Russel MB, Rasmussen BK, Thorvaldsen P, Olesen J. Prevalence and sex-ratio of the subtypes of migraine. Int J Epidemiol 1995; 24 : 612-618.

[3] Ophoff RA, Terwindt GM, Vergouwe MN, et al. Familial hemiplegic migraine and episodic ataxia type 2 are caused by mutations in the Ca2 + channel gene CACNL1A4. Cell 1996; 87: 543-52.

[4] De Fusco M, Marconi R, Silvestri L, et al. Haploinsufficiency of ATP1A2 encoding the Na+/K+ pump alpha-2 subunit associated with familial hemiplegic migraine type 2. Nat Genet 2003; 33: 192-196.

[5] May A, Ophoff RA, Terwindt GM, et al. Familial hemiplegic migraine locus on $19 \mathrm{q} 13$ is involved in the common forms of migraine with and without aura. Hum Genet 1995; 96: 604-608.

[6] Nyholt DR, Lea RA, Goadsby PJ, Brimage PJ, Griffiths LR. Familial typical migraine: linkage to chromosme 19p13 and evidence for genetic heterogeneity. Neurology 1998; 50: 1428-1432.

[7] Terwindt GM, Ophoff RA, Haan J, et al. The clinical expression of mutations in the P/Q-type calcium channel gene in familial hemiplegic migraine. Neurology 1998; 50: 1105-1110.

[8] Terwindt GM, Ophoff RA, van Eijk R, et al. Involvement of the CACNA1A gene containing region on $19 \mathrm{p} 13$ in migraine with and without aura. Neurology 2001; 56: 1028-1032.

[9] Jones KW, Ehm MG, Pericak-Vance MA, Haines JL, Boyd PR, Peroutka SJ. Migraine with aura susceptibility locus on chromosome $19 \mathrm{p} 13$ is distinct from the familial hemiplegic migraine locus. Genomics 2001; 78: 150-154.
[10] McCarthy LC, Hosford DA, Riley JH, et al. Single-nucleotide polymorphism alleles in the insulin receptor gene are associated with typical migraine Genomics 2001; 78: 135-149.

[11] Joutel A, Corpechot C, Ducros A, et al. Notch3 mutations in CADASIL, a hereditary adult-onset condition causing stroke and dementia. Nature 1996; 383: 707-710.

[12] Joutel A, Corpechot C, Ducros A, et al. Notch3 mutations in cerebral autosomal dominant arteriopathy with subcortical infarcts and leukoencephalopathy. CADASIL, a mendelian condition causing stroke and vascular dementia. Ann N Y Acad Sci 1997; 826: 213-7.

[13] Joutel A, Vahedi K, Corpechot C, et al. Strong clustering and stereotyped nature of Notch 3 mutations in CADASIL patients. Lancet 1997; 350(9090): 1511-15.

[14] Joutel A, Tournire-Lasserve E. Notch signalling pathway and human diseases. Semin Cell Dev Biol 1998; 9: 619-25.

[15] Hutchinson M, O'Riordan J, Javed M, et al. Familial hemiplegic migraine and autosomal dominant arteriopathy with leukoencephalopathy. CADASIL. Ann Neurol 1995; 38: 817-824.

[16] Verin M, Rolland Y, Landgraf F, et al. New phenotype of the cerebral autosomal dominant arteriopathy mapped to chromosome 19: migraine as the prominent clinical feature. J Neurol Neurosurg Psychiat 1995; 59: 579-585.

[17] Vahedi K, Chabriat H, Levy C, Joutel A, Tournier-Lasserve E, Bousser MG. Migraine with aura and brain magnetic resonance imaging abnormalities in patients with CADASIL. Arch Neurol 2004; 61(8): 1237-40.

[18] Oberstein SAJL, van den Boom R, Middelkoop HAM, et al. Incipient CADASIL. Arch Neurol 2003; 60: 707-712.

[19] Schwaag S, Evers S, Schirmacher A, Stögbauer F, Ringelstein EB, Kuhlenbäumer G. Genetic variants of the NOTCH3 gene in migraine--a mutation analysis and association study. Cephalalgia 2006; 26(2): 158-61.

[20] Borroni B, Brambilla C, Liberini P, Rao R, Archetti S, Venturelli E, Gipponi S, Caimi L, Padovani A. Investigating the association between Notch3 polymorphism and migraine. Headache 2006; 46(2): 317-21.

[21] Goodwin RG, Alderson MR, Smith CA, et al. Molecular and biological characterization of a ligand for CD27 defines a new family of cytokines with homology to tumor necrosis factor. Cell 1993; 73: 447-456.

[22] Rainero I, Grimaldi LM, Salani G, et al. Association between the tumor necrosis factor-alpha -308 G/A gene polymorphism and migraine. Neurology 2004; 62(1): 141-3.

[23] Empl M, Sostak P, Riedel M, et al. Decreased sTNF-RI in migraine patients? Cephalalgia 2003; 23(1): 55-8.

[24] Trabace S, Brioli G, Lulli P, et al. Tumor necrosis factor gene polymorphism in migraine. Headache 2002; 42(5): 341-5.

[25] Headache Classification Subcommittee of the International Headache Society. The international classification of headache disorders $2^{\text {nd }}$ edition. Cephalalgia 2004; 24(suppl 1).

[26] Blin N, Stafford DW. Isolation of high molecular-weight DNA. Nucleic Acids Res 1976; 3: 2303.

[27] Miller SA, Dykes DD, Plensky HF. A simple salting out procedure for extracting DNA from human nucleated cells. Nucleic Acid Res 1988; 16: 1215.

[28] Markus HS, Martin RJ, Simpson MA, et al. Diagnostic strategies in CADASIL. Neurology 2002; 59: 1134-1138. 